\title{
Stimulus-Response Analysis of Spatial Behaviour Pattern in Hospital Public Waiting Room
}

\author{
Vippy Dharmawan ${ }^{1 *}$, Rofi' ${ }^{1}{ }^{1}$, Nanik Rachmaniyah ${ }^{2}$ \\ ${ }^{1}$ Architecture Department, Universitas Muhammadiyah Surabaya, Surabaya 60113, Indonesia \\ ${ }^{2}$ Interior Department, Institut Teknologi 10 Nopember, Surabaya 59172, Indonesia \\ *Corresponding author. Email: vippy.dharmawan@ft.um-surabaya.ac.id
}

\begin{abstract}
Waiting room is a part of a building in which people sit or stand until their turn come. The way people behave in that area need to be predicted, thus architects can make good designs. This study aims to reveal the spatial behaviour patterns of visitors in public waiting rooms that located at Surabaya Hajj Hospital in Surabaya, Indonesia. The method used in this study is qualitative descriptive. By using behaviour mapping and stimulus response analysis, the patterns of people's behaviour can be identified. The comparation analysis of three waiting areas revealed that reception desks, waiting chairs, and queueing machine acted as main stimulus, which significantly influences visitor circulation patterns. Moreover, registration table was the most powerful stimulus among the three, and queueing machine was the weakest one. This result can be a reference in the design process for architects and designers.
\end{abstract}

Keywords: public waiting room, spatial behaviour, hospital

\section{INTRODUCTION}

Architecture and other built environments exist for the benefit of humans. There is no architecture or buildings that are built without a specific purpose. Architecture also has a variety of functions. According to Broadbent, one of the main functions of architecture is to accommodate the activities of building users who behave in it [1]. By understanding the process of human behaviour, designers can predict the behaviour that will occur, so mistakes in designing can be avoided. In addition, assessing how well a proposed design will meet the needs of its intended users is one of the main challenges that architects face during the design process. Whereas, on the other hand, the systematic evaluation of buildings, as far as human behaviour is concerned, is currently made possible only after they are built and used. Therefore, by understanding behavioural theories, architects can produce designs suitable for their users.

Human behaviour can be explained and predicted using various theories. Most of which depart from the discipline of psychology. Hall and Lindzey explained that there are two groups of theories that can explain the relationship between human behaviour and the environment. The two theory groups are the behaviouristic theory group and the holistic theory group. The behaviouristic theory group emphasizes more visible behaviours, while the holistic theory emphasizes the overall aspects of human beings and the environment [2].

To find out which of the two groups of theories can explain human behaviour in the public space better, Rachmaniyah made a comparison of two theories, which are StimulusResponse (S-R) theory from behaviouristic theory groups and field theory from holistic theory groups [3]. S-R theory is a concept in psychology that refers to the belief that behaviour manifests as a result of the interplay between stimulus and response. From this perspective it can be said that human behaviour will not occur without precedence by a stimulus that comes from the surrounding environment. Whereas, field theory is a psychological theory which examines patterns of interaction between the individual and the total field, or environment [4]. Field theory usually is expressed by a formula: $\mathrm{B}=\mathrm{f}(\mathrm{p}, \mathrm{e})$, meaning that behaviour (B) is a function of the person (p) and their environment (e). In area of psychology, the two theories discuss the basics of human behaviour from a different perspective. The S-R theory argues that human behaviour is a response from an environmental stimulus. Whereas, field theory holds that human behaviour is a function of his living space. A comparison of these two theories is carried out with the parameters of the process of human behaviour that is proposed by Patricous [5]. The results of the comparison of the two theories show that the S-R theory is better to explain and predict the occurrence of human behaviour than field theory. Therefore, by using S-R theory, designers can produce a public area environment that is more suitable for the behaviour of its users. The results are strengthened by a study conducted in the atrium area of a shopping center in Indonesia. The research showed there are interelation betwen behaviour pattern and physical setting in this area [3].

$\mathrm{S}-\mathrm{R}$ theory is widely used to explain human behaviour in economics, social, medicine, and other various fields. In economic field, the study about online impulsive buying behaviour in Lahore, Pakistan was guided by impulse buying literature and "Stimulus-Organism Response (S-OR) model". It explores the relationship between individual differences and impulse buying behaviour directly and indirectly through the mediating role of positive mood [6]. Similar study about Alipay brand image held by Yang in China was also conducted [7]. This study employed the theory of stimuli-organism-response (SOR), while adapted 
the theory of planned behaviour (TPB) and technology of acceptance model (TAM) in conceptualizing the stimuli construct. Other study was about human habits that are considered to be an important root of societal problems. The study addressed the conceptualization and operationalization of habits in the current literature and note that claims about the role of habits in societal context rarely agree with the basic definition of habits as goal-independent behaviour [8].

Whereas, there were not much research on waiting room design that addresse the overt behaviour of visitors. For example, a study held by Watts revealed the influence of soundscape and interior design on anxiety and perceived tranquillity of patients in a healthcare setting. The study described the effects of introducing natural sounds and large images of natural landscapes into a waiting room in a student health center. The results showed that levels of reported tranquillity were significantly improved but there were smaller change in reported reductions in anxiety [9]. Whereas, similar study in hospital explored the impact of two types of holistic artistic waiting room transformations on waiting experience and behaviour [10].

Based on Rachmaniyah, this paper discusses waiting rooms from different perspective. It focuses on the overt behaviour of visitors and interrelation between visitor circulation and the elements of interior. Previous similar study was conducted in a fast-food restaurant and revealed that formation of furniture and full wall glass window became main stimulus and could affect the visitors behaviour pattern [11].

\section{METHOD}

This was a qualitative research that was conducted in natural settings. The research setting was located in Surabaya Hajj Hospital in Indonesia. This hospital is a public hospital managed by government with more than 400 beds for patients. Three waiting room areas had been observed, namely: pharmacy area, BPJS (health insurance) area, and non BPJS area (Figure 1).

Behaviour information was obtained by direct observation of hospital patients so researchers could closely observe the phenomenon of research by acting as observers or as active and inactive participants. The observation was done using behavioural mapping method. This was a direct-observation technic that tracks people's behaviour in specific space and time. This method was started to be used in the late 1960's to study how physical environment features affect the people's behaviour, including the activity level, type of activity, etc. [12]. It has been used to study people's behaviours in many places such as health facilities, school, supermarket, children-care centre and grocery stores.
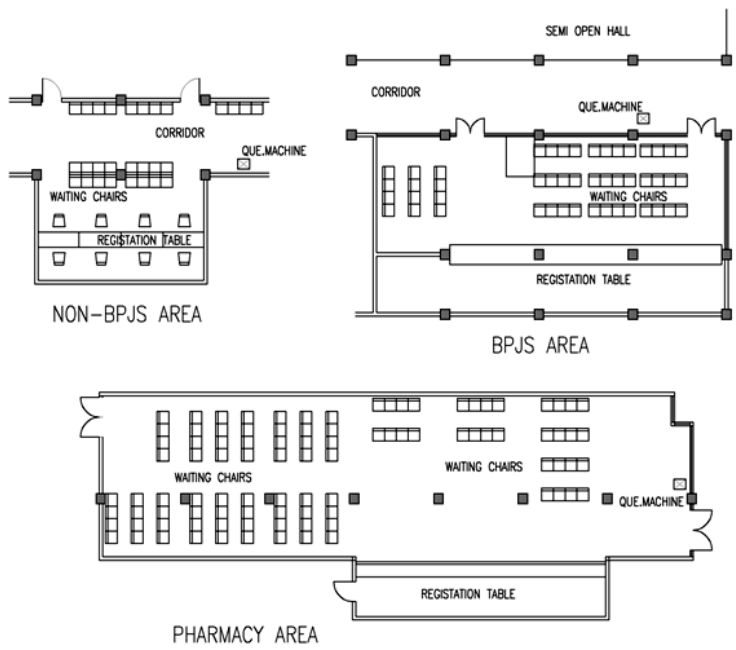

Figure 1 Waiting rooms in three area

Observations were made at peak and off-peak hours. There were at least five times observation for each area. Observers used a layout of map to record the positions of individuals, their movement, the time they spent in waiting area, and some parts of the rooms that were considered as influential to visitors' behaviour. In this case visitors' behaviour were categorized in moving and stationary behaviours.

\section{RESULTS AND DISCUSSION}

The waiting rooms were observed in three areas, i.e. pharmacy area, BPJS (health insurance) patient registration area, and non BPJS patient area. One of them occupied a space that was directly connected to the corridor in which hospital visitors were passing. The waiting room in the BPJS area was bigger than that for non BPJS patients. This is because the number of patients who used health insurance was higher than those who did not use insurance.

Initial observation showed that the atmosphere in the waiting room was quite roomy, except for the waiting room for BPJS patients. The waiting room in the pharmacy area felt spacious because there was wall-wide window on one side of the room, which allowed visitors to look outside the room. The waiting room for non BPJS patients felt roomy because it was directly related to the open area in the corridor. Whereas, the waiting room in the BPJS area felt cramped because the patients' outward vision was blocked by curtains that were always closed.

Subsequent observation showed that there were three elements of space that became visitors' stationary points, i.e. registration table, waiting chairs, and queuing machines. Throughout the service time, visitors appeared walking back and forth from the door (or corridor) to the three stationary points. Circulation of visitors showed certain patterns that continued to repeat from time to time. Besides, in the three observation areas, there were similarities in the circulation patterns of visitors. Researchers categorized them into patterns of type A to type G.

Figures 2 and 3 show the types of circulation patterns in the observed waiting rooms. In type A visitors entered the area then stop at the queuing machine to retrieve a number. Next, 
they headed for a row of waiting chairs, sat there, and waited their turn to be called. When their name was called through the loudspeaker, they went to the reception desk and did the registration process. After the registration process, they walked to the door and left the room. Whereas, in the type B pattern it appeared that visitors skipped the receiving machine and go straight to the reception desk. After being told by the clerk at the reception desk, they were forced to return to the registration machine to take the queue number. Furthermore, they headed for the waiting chair and waited for their turn to be called.
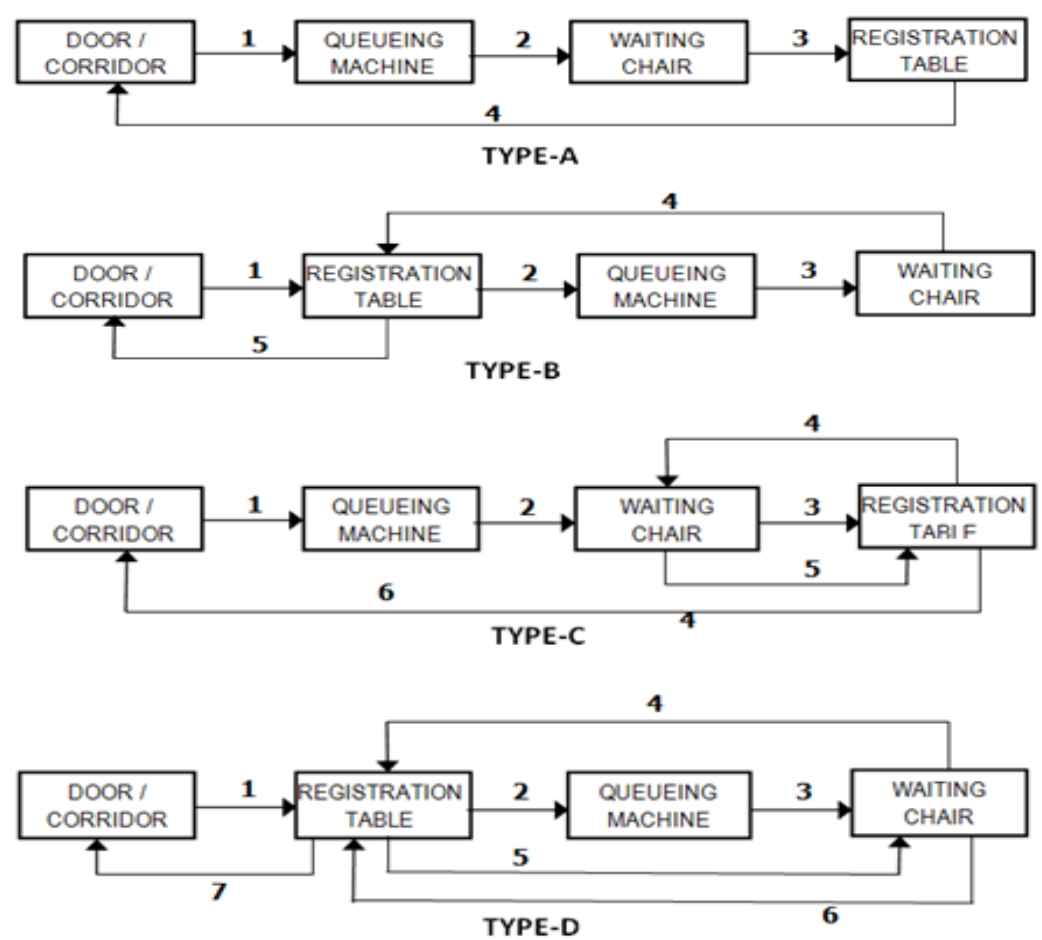

Figure 2 Circulation type A, B, C, and D

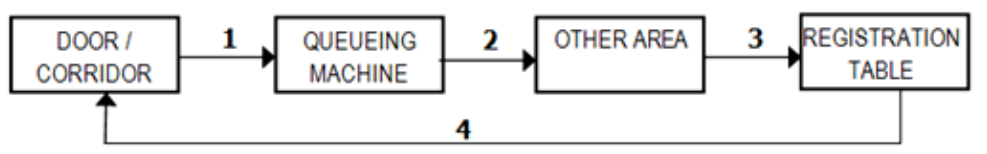

TYPE-E

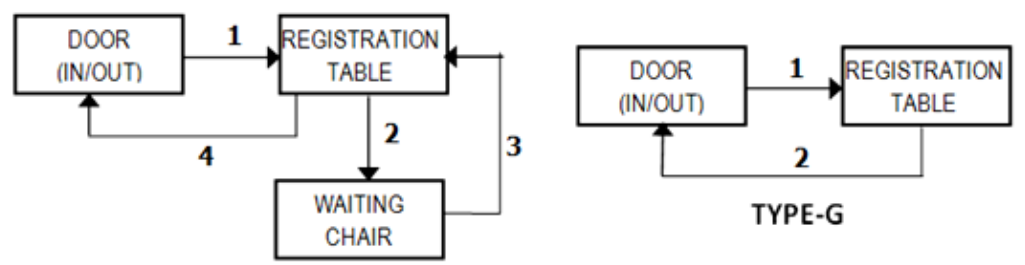

TYPE-F

Figure 3 Circulation type E, F, and G

Service at the reception desk sometimes took long time and visitors had to wait a while in the waiting chairs. The type $\mathrm{C}$ pattern as seen in figure 4 shows that visitors who have arrived in turn to be served by the receptionist are welcome to wait again in the waiting chair. A few moments later they returned to the reception desk and left the room after the process was over. This pattern was most often found in the pharmacy area in which the pharmacist needed to confirm the type and price of the drug the patients were asking for. Whereas, the type $D$ pattern was a type $C$ variant in which visitors skipped the queuing machine near the entrance. There were also visitors who were more likely to wait outside the waiting room area. This commonly occurred in waiting rooms in the BPJS area. In front of this area there was a semi-open hall surrounded by a wide corridor and food court. There was a music stage in the middle of the hall 
that also functioned as a waiting room. Visitors who had taken a queue number and knew that their turn was still long tended to wait in this area. Researchers categorized this pattern as type $\mathrm{E}$.

Type F pattern was the simplest patterns. Visitors entered the area from the door or corridor, then headed straight to the reception desk. A moment later they left the room from the same door. Most of this pattern occurred when the room was empty. Variant of pattern $F$ was pattern $G$ in which visitors enter the room and went to the reception desk. After that, they sat briefly in the waiting chairs, and then, when their number was called, they returned to the reception desk and then left the room.

Table 1 shows the comparison of stationary points of the available circulation types. It appeared that most types of circulation involved three elements of space as stationary points, namely registration table, waiting chairs, and queuing machine. Of the 7 types of circulation patterns, 5 of them involved these three elements together. This indicated that these three elements were the main stimulus that influenced the formation of visitor circulation patterns. Comparisons in the table also showed that the reception desk was the most stationary point visited by visitors. This indicated that the reception desk became the most powerful stimulus among the three main elements.

Furthermore, the comparison of type A with B and type C with $\mathrm{D}$ showed the phenomenon of queuing machines that were missed when not attended by officers. It appeared that the queuing machine was not strong enough to be a stimulus that might attract the attention of visitors. To be a strong stimulus, it needed to be accompanied by officers whose role was to direct visitors to use queuing machine.

Table 2 shows a comparison of visitor circulation during peak and off-peak hours in the three areas. During off-peak hours there were no significant differences between the three waiting rooms. The dominant circulation patterns were type $\mathrm{F}$ and type $\mathrm{G}$. Whereas, during peak hours, the circulation patterns that occurred in each room were different. In the BPJS waiting room the prominent pattern was type F. In the non BPJS area the dominant pattern was type A. Whereas, in the pharmacy area the dominant pattern was type C.

The comparison shown in the table also showed that in an off-peak situation the queue machine was rarely used because there was no queue. This indicated that when offpeak condition occurred, the queuing machine did not become a stimulus for visitors' behaviour.

Table 1 Type of circulation and stationary point

\begin{tabular}{|c|c|c|c|c|c|}
\hline \multirow{2}{*}{$\begin{array}{c}\text { Type of } \\
\text { Circulation }\end{array}$} & \multicolumn{5}{|c|}{ Stationary Point } \\
\cline { 2 - 6 } & $\begin{array}{c}\text { Queueing } \\
\text { Machine }\end{array}$ & $\begin{array}{c}\text { Queueing } \\
\text { Mchne. + Officer }\end{array}$ & $\begin{array}{c}\text { Registration } \\
\text { Table }\end{array}$ & Waiting Chairs & Others \\
\hline Type - A & never & 1 times & 1 times & 1 times & never \\
\hline Type - B & 1 times & never & 2 times & 1 times & never \\
\hline Type - C & never & 1 times & 2 times & 2 times & never \\
\hline Type - D & 1 times & never & 3 times & 2 times & never \\
\hline Type - E & never & 1 times & 1 times & never & 1 times \\
\hline Type - F & never & never & 2 times & 1 times & never \\
\hline Type-G & never & never & 1 times & never & never \\
\hline
\end{tabular}

Table 2 Waiting area and type of circulation

\begin{tabular}{|c|c|c|c|c|c|c|c|c|}
\hline \multirow{2}{*}{ Area } & \multirow{2}{*}{ Time } & \multicolumn{6}{|c|}{ Type of Circulation } & \multirow[b]{2}{*}{ Type G } \\
\hline & & Type A & Type B & Type C & Type D & Type E & Type F & \\
\hline \multirow{2}{*}{$\begin{array}{c}\text { Pharmacy } \\
\text { Area }\end{array}$} & Peak Hour & 0 & 0 & 3 & 1 & 0 & 1 & 0 \\
\hline & Off Peak Hour & 0 & 0 & 1 & 1 & 0 & 2 & 0 \\
\hline \multirow{2}{*}{ BPJS Area } & Peak Hour & 3 & 1 & 0 & 0 & 3 & 0 & 0 \\
\hline & Off Peak Hour & 1 & 1 & 0 & 0 & 1 & 1 & 2 \\
\hline \multirow{2}{*}{$\begin{array}{c}\text { non BPJS } \\
\text { Area }\end{array}$} & Peak Hour & 3 & 1 & 0 & 0 & 0 & 0 & 0 \\
\hline & Off Peak Hour & 1 & 1 & 0 & 0 & 0 & 1 & 2 \\
\hline
\end{tabular}

\section{CONCLUSION}

In the public waiting room, the elements of space, such as registration tables, waiting chairs, and queuing machines are the main stimuli that influence the spatial behaviour patterns of visitors. This phenomenon is indicated by the tendency of visitors who are always in a stationary position at these three points. In addition, it can also be concluded that the registration table is the most powerful stimulus among the three. This is indicated by the phenomenon of visitors who have never missed this element when entering the waiting room area. Whereas, the weakest stimulus of the three elements of space is the queuing machine. This can be seen when the queuing machine is not attended by officers, 
visitors tend not to notice it. In order for the queuing machine to be a strong stimulus, officers need to stand near it so that visitors do not miss this tool. For designers, these findings are very useful. It can be a reference in the design process. The fact that the three elements of space, i.e. registration table, waiting chairs, and queuing machines become the main stimulus for the formation of visitor behaviour patterns, lead to the conclusion that the three elements are the most taken into account in the waiting room design process. During the design process the designer can arrange the placement of the three elements as a first step in arranging the room. Furthermore, the other elements of space will follow the pattern of the placement of these three elements.

\section{REFERENCES}

[1] G. Broadbent, Design in Architecture. London: John Wiley \& Sons, 1973.

[2] C. S. Hall and G. Lindzey, "Personality theory in perspective.," in Theories of personality., 2006.

[3] N. Rachmaniyah, "Behaviour Theories and Public Space,” Jurnal Desain Idea, vol. 14, no. 1, 2011.

[4] M. Jarvis, Theoretical Approaches in Psychology. London: Routledge, 2000.

[5] S. K. Terian and J. Lang, "Creating Architectural Theory: The Role of the Behavioural Sciences in Environmental Design," Journal of Architectural Education (1984-), 1988.

[6] M. Ahmad, H. Ali, M. Malik, A. Humayun, and S. Ahmad, "Factors Affecting Impulsive Buying
Behaviour with Mediating role of Positive Mood: An Empirical Study," European Online Journal of Natural and Social Sciences, 2019.

[7] A. Yang and C. C. Tan, "A Stimulus-organismresponse Model To Structure Alipay Consumer Perceptions In China," ASEAN/Asian Academic Society International Conference Proceeding Series, 2018.

[8] H. Marien, R. Custers, and H. Aarts, "Studying Human Habits in Societal Context: Examining Support for a Basic Stimulus-Response Mechanism," Current Directions in Psychological Science, 2019.

[9] G. Watts, A. Khan, and R. Pheasant, "Influence of soundscape and interior design on anxiety and perceived tranquillity of patients in a healthcare setting," Applied Acoustics, 2016.

[10] H. Klingemann et al., "Public art and public space - Waiting stress and waiting pleasure," Time and Society, 2018.

[11] V. Dharmawan, "Study of Behaviour in Fastfood Restaurant at Shopping Mall," Jurnal Desain Interior, vol. 3, no. 2, 2018.

[12] N. G. Cosco, R. C. Moore, and M. Z. Islam, "Behaviour mapping: A method for linking preschool physical activity and outdoor design," Medicine and Science in Sports and Exercise, 2010.

[13] Supardi, Effective Schools, Basic Concepts \& Practices. Jakarta: Rajawali Press, 2013. 